\title{
Methyl Jasmonate and Salinity Increase Anthocyanin Accumulation in Radish Sprouts
}

\author{
Masaru Sakamoto *(1) and Takahiro Suzuki \\ Faculty of Biology-Oriented Science and Technology, Kindai University, Wakayama 649-6493, Japan \\ * Correspondence: sakamoto@waka.kindai.ac.jp
}

Received: 8 July 2019; Accepted: 15 August 2019; Published: 2 September 2019

check for updates

\begin{abstract}
Plant secondary metabolites with antioxidant properties, such as anthocyanins, are considered to have an important commercial value for some crops. Although anthocyanin concentration increases in response to various stimuli in plants, the mechanism of anthocyanin accumulation under multiple stimuli is not yet well understood. Here, we examined the effects of methyl jasmonate (MJ) and salinity on anthocyanin accumulation in radish (Raphanus sativus) sprouts. MJ treatments induced anthocyanin accumulation, which was enhanced by simultaneous treatment with salinity $(200 \mathrm{mM} \mathrm{NaCl})$, accompanied by growth restrictions. Sprouts treated with salinity alone did not induce anthocyanin accumulation, although sprout growth was restricted. Co-treatment with MJ and salinity increased hydrogen peroxide, total phenol content, and radical scavenging capacity more strongly than was achieved when each treatment was applied singly. Accumulation of anthocyanin was dependent on $\mathrm{NaCl}$ concentration and light intensity. Changing MJ and salinity treatment periods had different effects on anthocyanin accumulation and growth restriction, indicating that these phenomena might be differentially regulated. These results may provide an effective anthocyanin accumulation method without reducing plant biomass.
\end{abstract}

Keywords: anthocyanin; methyl jasmonate; salinity; radish sprouts; treatment period

\section{Introduction}

Plants activate secondary metabolic pathways in response to various environmental stresses such as light, temperature, salinity, drought, and pathogens [1,2]. Severe exposure to these stresses causes disruption of plant cellular homeostasis, which is accompanied by the production of reactive oxygen species (ROS). To mitigate stress-induced cellular oxidative damage, plants accumulate antioxidant secondary metabolites and antioxidative enzymes [3-5]. Under salinity stress, plants initiate the synthesis of phenolic compounds and other antioxidants, and free radical scavenging enzymes to reduce ROS-mediated oxidative damage [6,7]. The importance of the antioxidant machinery under salinity stress has also been reported in transgenic plants, which accumulate increased concentrations of antioxidants or antioxidative enzymes, showing increased salinity tolerance [8-10].

Production of anthocyanins, phenolic compounds that are well known as the principal plant pigments conferring red coloration, is induced in response to various stresses, and anthocyanins act as antioxidant molecules in plants to achieve tolerance of oxidative stress [11,12]. In red leaf lettuce, low root-zone temperature stress resulted in increased antioxidant capacity and anthocyanin accumulation in leaves [13]. In salinity stress experiments, anthocyanin production was observed in a salt-concentration-dependent manner in tomato and sugarcane [14,15]. Salt-tolerant rice genotypes contained higher concentrations of anthocyanin and proline compared with salt-sensitive genotypes [16], indicating the importance of anthocyanins in plant salinity response.

Jasmonic acid (JA) and methyl jasmonate (MJ) are produced in response to biotic and abiotic stresses, and they are involved in local and systemic responses, including the synthesis of several 
groups of secondary metabolites such as phenolic compounds [5,17]. MJ treatment itself can elicit the production of ROS, the activation of antioxidative enzymes, and the accumulation of phenolic compounds, including anthocyanins [18-24]. In several plant species, MJ treatment triggered anthocyanin accumulation, concomitant with the expression of a series of genes involved in the biosynthesis of anthocyanins [17,22,25]. MJ induced expression of anthocyanin biosynthesis genes in the presence of light through the expression of MYB transcription factors [26].

Due to their high antioxidant capacity, anthocyanins are also regarded as important contributors to the colors of fruits and vegetables, and to nutrition for promotion of human health $[27,28]$. In several plant species, treatment of pre- and post-harvested fruits with MJ enhanced the anthocyanin concentration of the fruits [19,29-31]. In vegetables, various environmental factors stimulated the production of anthocyanins in leaves, such as temperature, light, carbon dioxide, and various stresses [32-34]. These results suggest the existence of multiple signal cascades leading to anthocyanin synthesis. Multiple stimuli working in combination were shown to enhance anthocyanin production more strongly than was achieved when these stimuli are applied singly in several plant species [24,35-37]. Here, using radish (Raphanus sativus L.) sprouts as the experimental material, we examined the simultaneous effects of MJ and salinity on vegetative growth, anthocyanin accumulation, and antioxidant capacity.

\section{Materials and Methods}

Radish seeds (R. sativus cv. Taibyo-Soubutori; Takii Seed Co., Japan) were sown on wet paper towels and pregerminated for $2 \mathrm{~d}$ at $20^{\circ} \mathrm{C}$ in the dark. Sprouts at $2 \mathrm{~d}$ after sowing (DAS) were placed on well-watered sponge cubes $2 \times 2 \times 2 \mathrm{~cm}$ in size. To set the sprouts into the sponge cubes, each sponge cube was divided into two pieces, with the root of a germinated sprout being sandwiched between the two halves. MJ $(0.5 \mathrm{mM})$ was then sprayed on to the shoot of the sprouts. Control sprouts were sprayed with distilled water. After the spray treatments, sprouts were kept in the dark for $1 \mathrm{~h}$ at $20^{\circ} \mathrm{C}$ and were transferred to cultivation space at $20^{\circ} \mathrm{C}$ under $100 \mu \mathrm{mol} \mathrm{m} \mathrm{m}^{-2} \mathrm{~s}^{-1}$ photosynthetic photon flux (PPF) density under a 16-h light/8-h dark photoperiod, using fluorescent lamps (FL40SBR-A; NEC Co., Tokyo, Japan), unless otherwise mentioned. MJ treatments were repeated once daily from 2 to 4 DAS, unless otherwise mentioned. Salinity treatments were conducted just after the first MJ treatment by immersing the sponge cubes in $\mathrm{NaCl}$ solutions. Salinity treatments were continuously conducted from 2 to 7 DAS, unless otherwise mentioned. Sprouts without $\mathrm{NaCl}$ treatment were treated with distilled water. The volume of the immersion solution was $25 \mathrm{~mL}$ per cube. At 7 DAS, the sprouts were harvested, and the growth and component analyses were conducted. The dry weight was obtained by drying the plant materials at $80^{\circ} \mathrm{C}$ for 3 days. Shoot water content was obtained from the (SFW-SDW)/SFW ratio, where SFW and SDW were the shoot fresh weight and shoot dry weight, respectively. For microscopic analysis, sprout cotyledon sections were prepared by cutting the cotyledons including the veins using a sharp razor blade.

For investigating the effect of $\mathrm{NaCl}$ concentration, sprouts were treated with $0,50,100,200$, and $300 \mathrm{mM} \mathrm{NaCl}$ with or without MJ treatment. For investigating the effect of light intensity, sprouts were exposed to the light condition of $0,15,50,100$, and $200 \mu \mathrm{mol} \mathrm{m}^{-2} \mathrm{~s}^{-1}$ PPF. For investigating the effect of MJ treatment periods, MJ was sprayed on sprouts once daily from 2 to 4 DAS (M2-4), from 3 to 5 DAS (M3-5), and from 4 to 6 DAS (M4-6). For investigating the effect of $\mathrm{NaCl}$ treatment periods, $\mathrm{NaCl}$ was continuously treated from 2 to 7 DAS (N2-7), from 3 to 7 DAS (N3-7), from 4 to 7 DAS (N4-7), from 5 to 7 DAS (N5-7), 6 to 7 DAS (N6-7), from 2 to 6 DAS (N2-6), from 2 to 5 DAS (N2-5), from 2 to 4 DAS (N2-4), and from 2 to 3 DAS (N2-3). Each experiment was repeated at least three times independently with similar results.

The total phenol content was measured spectrophotometrically using the Folin-Ciocalteu method described previously [24], with slight modifications. Cotyledons ( $50 \mathrm{mg}$ fresh weight) were homogenized with $500 \mu \mathrm{L}$ of $90 \%$ methanol. The sample was then centrifuged at $10,000 \times g$ for $5 \mathrm{~min}$. The supernatant $(20 \mu \mathrm{L})$ was diluted with $680 \mu \mathrm{L}$ of distilled water, and $50 \mu \mathrm{L}$ of phenol reagent was mixed with it. 
After adding $300 \mu \mathrm{L}$ of $5 \%$ sodium carbonate, the mixture was incubated at $25{ }^{\circ} \mathrm{C}$ for $30 \mathrm{~min}$ in the dark. The absorbance of the supernatant was measured at $765 \mathrm{~nm}$, and a standard curve was prepared using gallic acid.

The anthocyanin content was measured spectrophotometrically as described previously [24], with modifications. Fresh cotyledons were promptly dried in an oven at $90^{\circ} \mathrm{C}$ for 1 day. Dried cotyledons were weighed (about $15 \mathrm{mg}$ ) and soaked in $1 \mathrm{~mL}$ of methanol containing $1 \% \mathrm{HCl}$ and were incubated at $95{ }^{\circ} \mathrm{C}$ for $15 \mathrm{~min}$. The sample was then cooled to room temperature. After the removal of the cotyledons, absorbance of the supernatant was measured at $533 \mathrm{~nm}$, and a standard calibration curve was prepared using cyanidin-3-glucoside.

Production of hydrogen peroxide in sprout cotyledons was investigated by $3,3^{\prime}$-diaminobenzidine (DAB) staining [13]. Cotyledons from sprouts at 7 DAS were detached and incubated with $1 \mathrm{mg} \mathrm{mL}^{-1}$ DAB solution ( $\mathrm{pH}$ 3.8) under light for $5 \mathrm{~h}$. To remove the chlorophyll, the cotyledons were boiled in $90 \%$ ethanol at $95^{\circ} \mathrm{C}$ for $3 \mathrm{~min}$. After cooling, photographs were taken after soaking the cotyledons in freshly prepared $90 \%$ ethanol solution.

The radical scavenging capacity was measured using 1,1-diphenyl-2-picrylhydrazyl (DPPH) radicals as previously described [38], with minor modifications. Cotyledons (50 $\mathrm{mg}$ fresh weight) were homogenized with $500 \mu \mathrm{L}$ of $90 \%$ methanol. The sample was then centrifuged at $10,000 \times g$ for $5 \mathrm{~min}$. The supernatant $(40 \mu \mathrm{L})$ was mixed with $400 \mu \mathrm{L}$ of $0.5 \mathrm{mM}$ DPPH in ethanol and $360 \mu \mathrm{L}$ of methanol. After $30 \mathrm{~min}$ incubation, the absorbance was monitored at $517 \mathrm{~nm}$. DPPH radical scavenging capacity was expressed as the percentage of DPPH radicals scavenged by calculating the difference between the pre-incubation and post-incubation absorbances.

The level of malondialdehyde (MDA, a lipid peroxidation product) was determined by the thiobarbituric acid reaction method [24]. Cotyledons (100 $\mathrm{mg}$ fresh weight) were homogenized in $0.5 \mathrm{~mL}$ of $0.1 \%$ trichloroacetic acid (TCA) solution. After centrifugation at $10,000 \times g$ for $5 \mathrm{~min}, 0.2 \mathrm{~mL}$ of the supernatant was added to $0.8 \mathrm{~mL}$ of $20 \%$ TCA solution (containing $0.5 \%$ thiobarbituric acid, TBA). The mixture was incubated at $95^{\circ} \mathrm{C}$ for $30 \mathrm{~min}$ and then transferred onto ice. After centrifugation at $10,000 \times g$ for $5 \mathrm{~min}$, the absorbance of the supernatant was measured at $532 \mathrm{~nm}$ and the nonspecific absorbance at $600 \mathrm{~nm}$ was subtracted. The concentration of MDA was quantified using a molar extinction coefficient of $155 \mathrm{mM}^{-1} \mathrm{~cm}^{-1}$.

The data obtained for each parameter were analyzed with the statistical package JMP (SAS Institute, Cary, NC, USA). Differences among treatments were determined by one-way analysis of variance (ANOVA). Mean comparisons were made using the Tukey-Kramer honestly significant difference multiple range test at $P<0.05$.

\section{Results}

\subsection{Effect of MJ and Salinity on Anthocyanin Accumulation and Sprout Growth}

MJ treatment of radish sprouts induced anthocyanin accumulation at 7 DAS (Figure 1). Simultaneous treatments with $\mathrm{MJ}$ and salinity $(200 \mathrm{mM} \mathrm{NaCl})$ significantly accelerated anthocyanin accumulation, whereas treatment with salinity alone did not induce anthocyanin accumulation (Figure 1). These anthocyanin accumulations were observed from one day after the start of treatments (data not shown). Red-colored pigments were observed on the abaxial surface of cotyledons of sprouts treated with MJ and MJ plus salinity (Figure 1c). In MJ-treated sprouts, anthocyanins were restricted in a layer of abaxial cells under the vein whereas in sprouts co-treated with MJ and salinity, and anthocyanin was widely dispersed in a layer of many abaxial cells (Figure 1c). Similar pigmentation was also observed in tartary buckwheat sprout cotyledons under cold stress [39]. The hypocotyl hardly turned red with any treatment (Figure 1c). MJ or salinity treatment alone decreased hypocotyl length and fresh weight of the sprouts. This decrease was greater in the salinity-treated sprouts (Figure 2a,b). Simultaneous treatments with MJ and salinity further reduced hypocotyl length and sprout fresh weight. Changes in dry weight and water content showed trends similar to those for fresh weight (Figure 2c,d). 
(a)

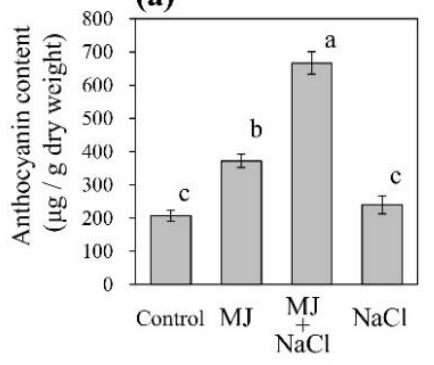

(b)

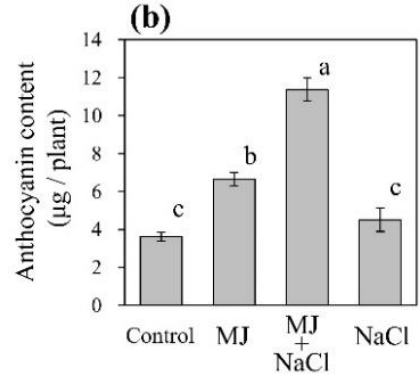

(c)

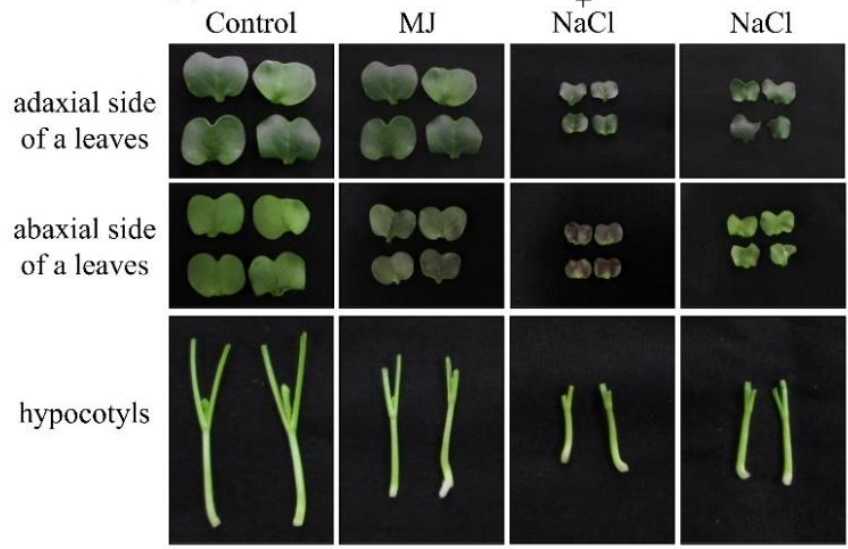

leaf section
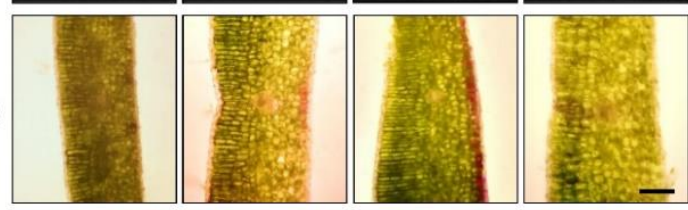

Figure 1. Simultaneous effect of methyl jasmonate (MJ) and salinity treatments on anthocyanin accumulation in radish sprouts. Anthocyanin contents of per unit dry weight (a) and anthocyanin content per plant (b) were measured after treatments with water (Control), $0.5 \mathrm{mM} \mathrm{MJ} \mathrm{(MJ),} 200 \mathrm{mM}$ $\mathrm{NaCl}(\mathrm{NaCl})$, and co-treatment with $0.5 \mathrm{mM} \mathrm{MJ}$ and $200 \mathrm{mM} \mathrm{NaCl}(\mathrm{MJ}+\mathrm{NaCl})$. (c) Morphological observation of anthocyanin distribution. Leaf sections were observed under a microscope. Scale bars, $200 \mu \mathrm{m}$. Error bars represent \pm SE $(n=13)$. Different letters indicate significant differences by Tukey's multiple comparison test $(P<0.05)$.

(a)

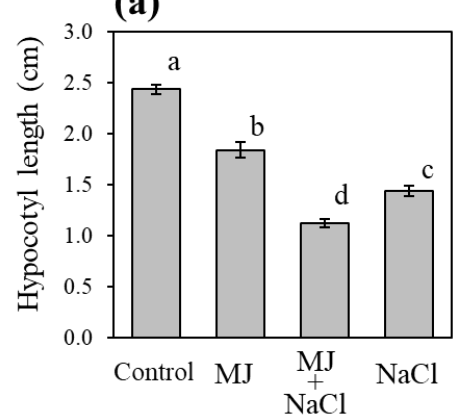

(c)

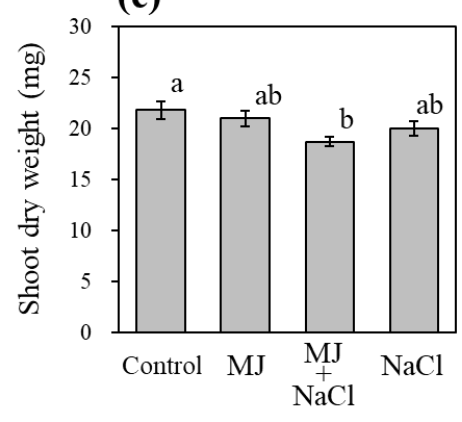

(b)

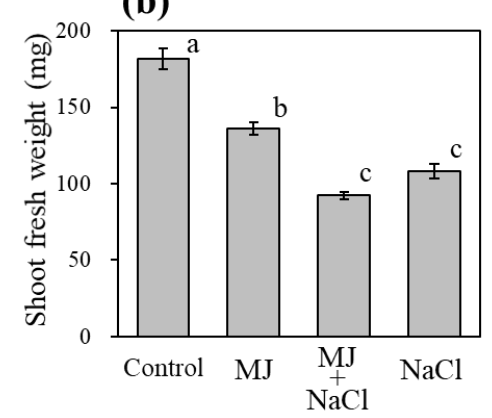

(d)

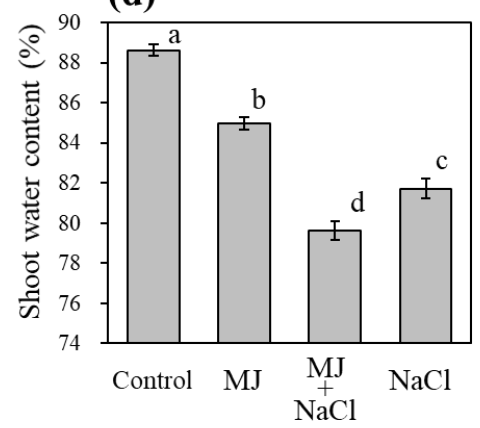

Figure 2. Simultaneous effect of MJ and salinity treatments on the growth of radish sprouts. Hypocotyl length (a), shoot fresh weight (b), shoot dry weight (c), and shoot water content (d) of sprouts after treatment with MJ $(0.5 \mathrm{mM})$ and/or salinity $(200 \mathrm{mM} \mathrm{NaCl})$. Error bars represent $\pm \mathrm{SE}$ (hypocotyl length and shoot fresh weight; $n=24$; shoot dry weight and water content; $n=16)$. Different letters indicate significant differences by Tukey's multiple comparison test $(P<0.05)$. 


\subsection{Effect of MJ and Salinity on Oxidative and Antioxidative Properties}

To examine the association between oxidative stress and anthocyanin accumulation, hydrogen peroxide production in sprouts treated with $\mathrm{MJ}$ and salinity was detected by DAB staining. Brown DAB precipitate was clearly observed in cotyledons treated with salinity alone and was enhanced in cotyledons co-treated with MJ and salinity (Figure 3a). The total phenol content was increased by MJ treatment alone and was enhanced by co-treatment with salinity (Figure 3b). Salinity treatment alone, as compared with MJ treatment alone, induced higher concentrations of total phenol (Figure $3 \mathrm{~b}$ ). Changes in DPPH, an indicator of radical scavenging capacity, followed trends similar to those of total phenol content (Figure 3c). The concentration of MDA, which is the product of oxidized lipids, was increased by single treatments of MJ or salinity to a similar extent as those of these phenolic compounds but was further enhanced by simultaneous treatment with both MJ and salinity (Figure 3d).

(a)

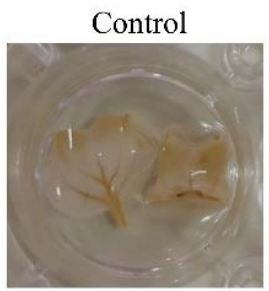

(b)

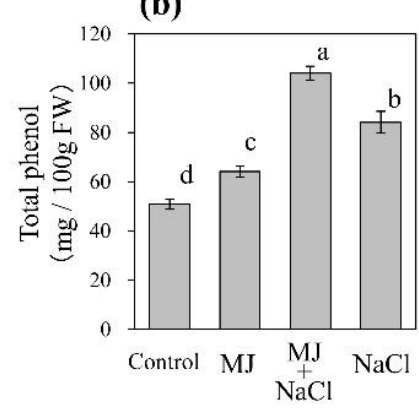

MJ

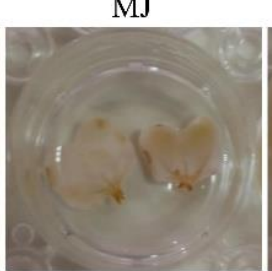

(c)

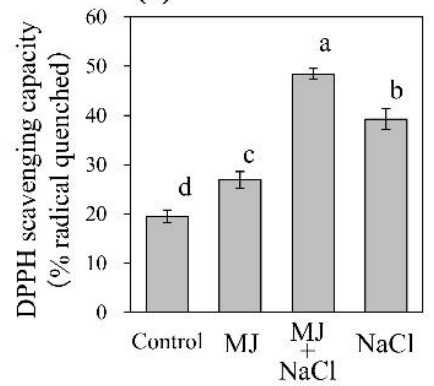
$\mathrm{NaCl}$
MJ
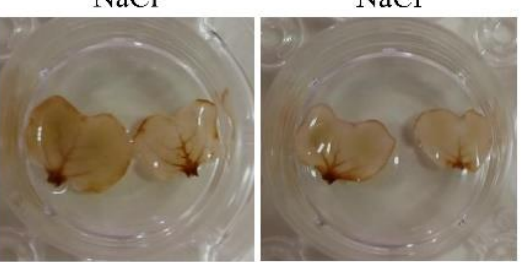

(d)

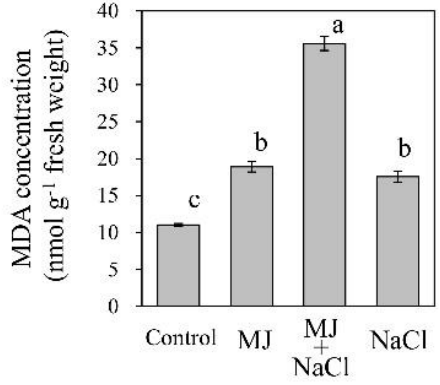

Figure 3. Simultaneous effect of MJ and salinity treatments on oxidative stress and antioxidant parameters in radish sprouts. Hydrogen peroxide production in cotyledons was detected by 3,3'-diaminobenzidine (DAB) stain (a), total phenol content (b), 1,1-diphenyl-2-picrylhydrazyl (DPPH) radical scavenging capacity (c), and malondialdehyde (MDA) concentration (d) of sprouts after treatment with MJ $(0.5 \mathrm{mM})$ and/or salinity $(200 \mathrm{mM} \mathrm{NaCl})$. Error bars represent $\pm \mathrm{SE}$ (total phenol content and DPPH; $n=9$, MDA; $n=6$ ). Different letters indicate significant differences by Tukey's multiple comparison test $(P<0.05)$.

\subsection{Effect of $\mathrm{NaCl}$ Concentration on Anthocyanin Accumulation}

Next, we investigated the effect of $\mathrm{NaCl}$ concentration on the accumulation of anthocyanins in sprouts in the presence or absence of MJ. In the presence of MJ, anthocyanin accumulation increased in a $\mathrm{NaCl}$ dose-dependent manner (Figure 4). At $300 \mathrm{mM} \mathrm{NaCl}$, the treatment induced anthocyanin accumulation in the absence of MJ (Figure 4). 


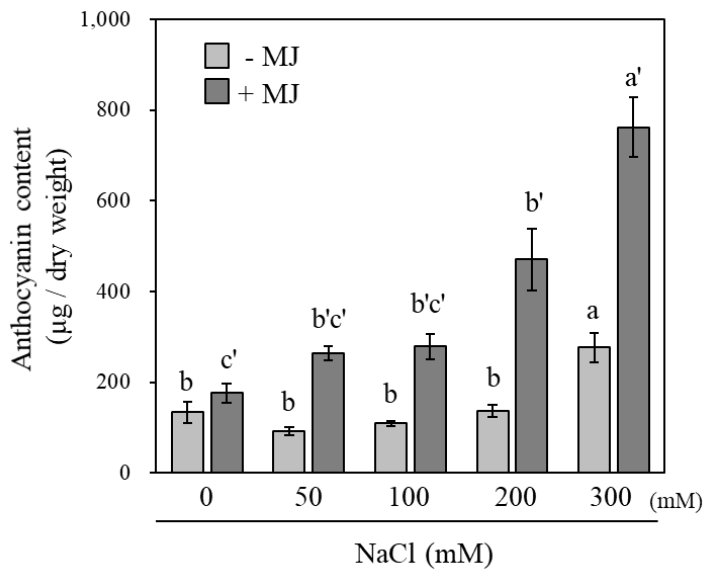

Figure 4. Effect of $\mathrm{NaCl}$ concentration on anthocyanin accumulation in radish sprouts co-treated with MJ. Anthocyanin contents were measured after exposure to 0,50, 100, 200, or $300 \mathrm{mM} \mathrm{NaCl}$ with or without $0.5 \mathrm{mM}$ MJ treatments. Vertical bars represent $\pm \mathrm{SE}(n=6)$. Significant differences were detected by Tukey's multiple comparison test $(P<0.05)$. Statistical analyses were performed separately for the sprout with or without MJ treatment, and results are shown by lower-case letters without and with single apostrophes, respectively.

\subsection{Effect of Light Intensity on Anthocyanin Concentration in Sprouts}

Light stimuli influenced the production of anthocyanins in leaves $[11,13,40]$. We thus examined the effect of light intensity on anthocyanin accumulation in the radish sprouts co-treated with MJ and salinity. Under dark conditions, anthocyanin accumulation was not detected in sprouts of all treatments (Figure 5). In sprouts co-treated with MJ and salinity, anthocyanin accumulation was clearly increased in a light intensity-dependent manner (Figure 5c). Under high light (200 $\left.\mu \mathrm{mol} \mathrm{m}^{-2} \mathrm{~s}^{-1} \mathrm{PPF}\right)$ conditions, sprouts treated with salinity alone showed a significantly greater anthocyanin accumulation than was achieved in sprouts treated with MJ alone (Figure $5 b, d$ ).
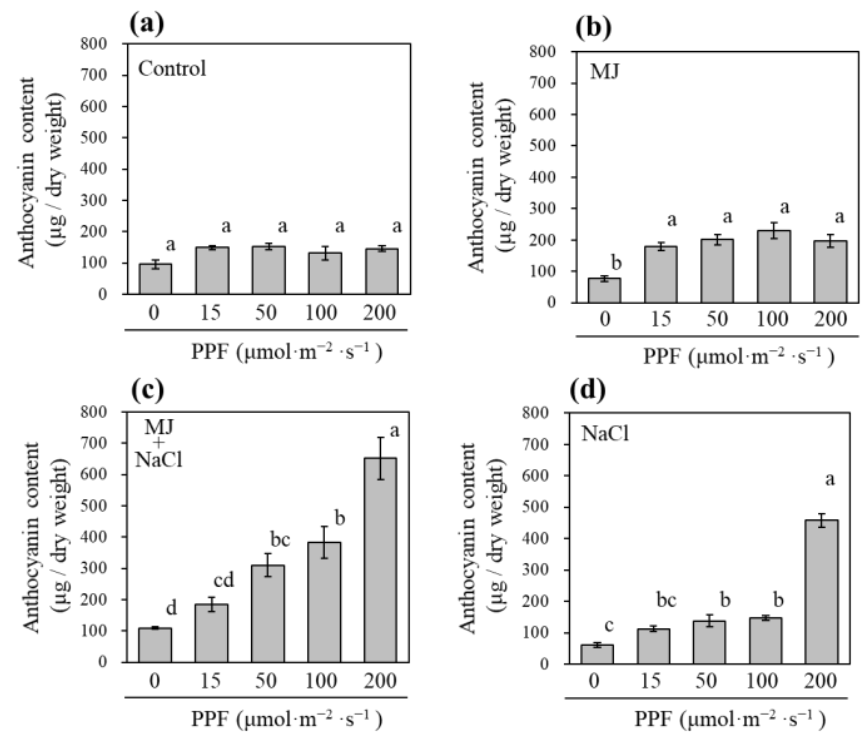

Figure 5. Effect of light intensity on the growth and anthocyanin accumulation in radish sprouts treated with MJ and salinity. Anthocyanin contents were measured after 0,15, 50, 100, or $200 \mu \mathrm{mol} \mathrm{m}^{-2} \mathrm{~s}^{-1}$ PPF light exposure (in a 16-h light/8-h dark photoperiod) from 2 days after sowing (DAS) of the sprouts treated with water (a), $0.5 \mathrm{mM} \mathrm{MJ} \mathrm{(b),} 200 \mathrm{mM} \mathrm{NaCl}$ (c), and the co-treatment with $0.5 \mathrm{mM} \mathrm{MJ}$ and $200 \mathrm{mM} \mathrm{NaCl}(\mathbf{d})$. Error bars represent $\pm \mathrm{SE}(n=6)$. Different letters indicate significant differences by Tukey's multiple comparison test $(P<0.05)$. 


\subsection{Effect of MJ Treatment Periods on Anthocyanin Accumulation}

To investigate the mechanism of anthocyanin accumulation and growth suppression induced by MJ and salinity treatments, singly or in combination, we examined the effect of changes in duration of MJ treatment on the accumulation of anthocyanins in sprouts co-treated with salinity (Figure 6a). Sprouts treated with MJ from 2 to 4 DAS (M2-4) showed higher anthocyanin accumulation as compared with sprouts treated from 3 to 5 DAS (M3-5) or from 4 to 6 DAS (M4-6) (Figure 6b). The reductions in hypocotyl length and water content through the M2-4 treatment was alleviated by delaying the MJ treatment period (Figure $6 \mathrm{c}, \mathrm{f})$. The fresh and dry weights of sprouts did not significantly change between all MJ/salinity co-treated sprouts and salinity-alone-treated negative control sprouts (M0) (Figure 6d,e).
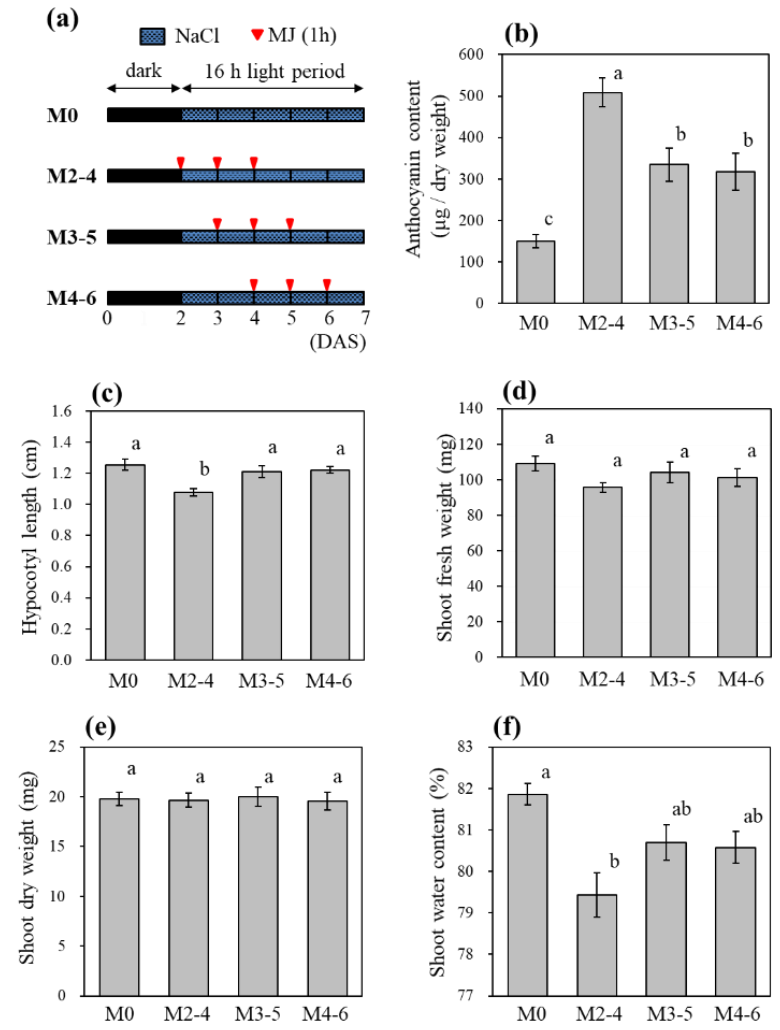

Figure 6. Effect of MJ $(0.5 \mathrm{mM})$ treatment periods on the growth and anthocyanin accumulation in radish sprouts co-treated with salinity $(200 \mathrm{mM} \mathrm{NaCl})$. (a) Schematic design of this experiment. Anthocyanin concentration (b), hypocotyl length (c), shoot fresh weight (d), shoot dry weight (e), and shoot water content $(\mathbf{f})$ were measured in sprouts of each treatment at 7 DAS. Error bars represent \pm SE $(n=9)$. Different letters indicate significant differences by Tukey's multiple comparison test $(P<0.05)$.

\subsection{Effect of Salinity Treatment Periods on Anthocyanin Accumulation}

Next, we examined the effect of the duration of the salinity treatment on the accumulation of anthocyanins in sprouts co-treated with MJ (Figure 7a). Anthocyanin accumulation observed in sprouts treated simultaneously with MJ and salinity (N2-7) was more effectively suppressed when salinity treatment start times were delayed (N4-7, N5-7, or N6-7), as compared with when salinity treatment end times were shortened (N2-5, N2-4, or N2-3) (Figure 7b). In contrast, the reductions in hypocotyl length, fresh weight, and water content of sprouts induced by co-treatment with $\mathrm{MJ}$ and salinity were more effectively alleviated in sprouts when the salinity treatment start time was delayed (Figure $7 \mathrm{c}, \mathrm{d}, \mathrm{f})$. The sprout dry weight did not change significantly among any of the treatments (Figure 7e). 

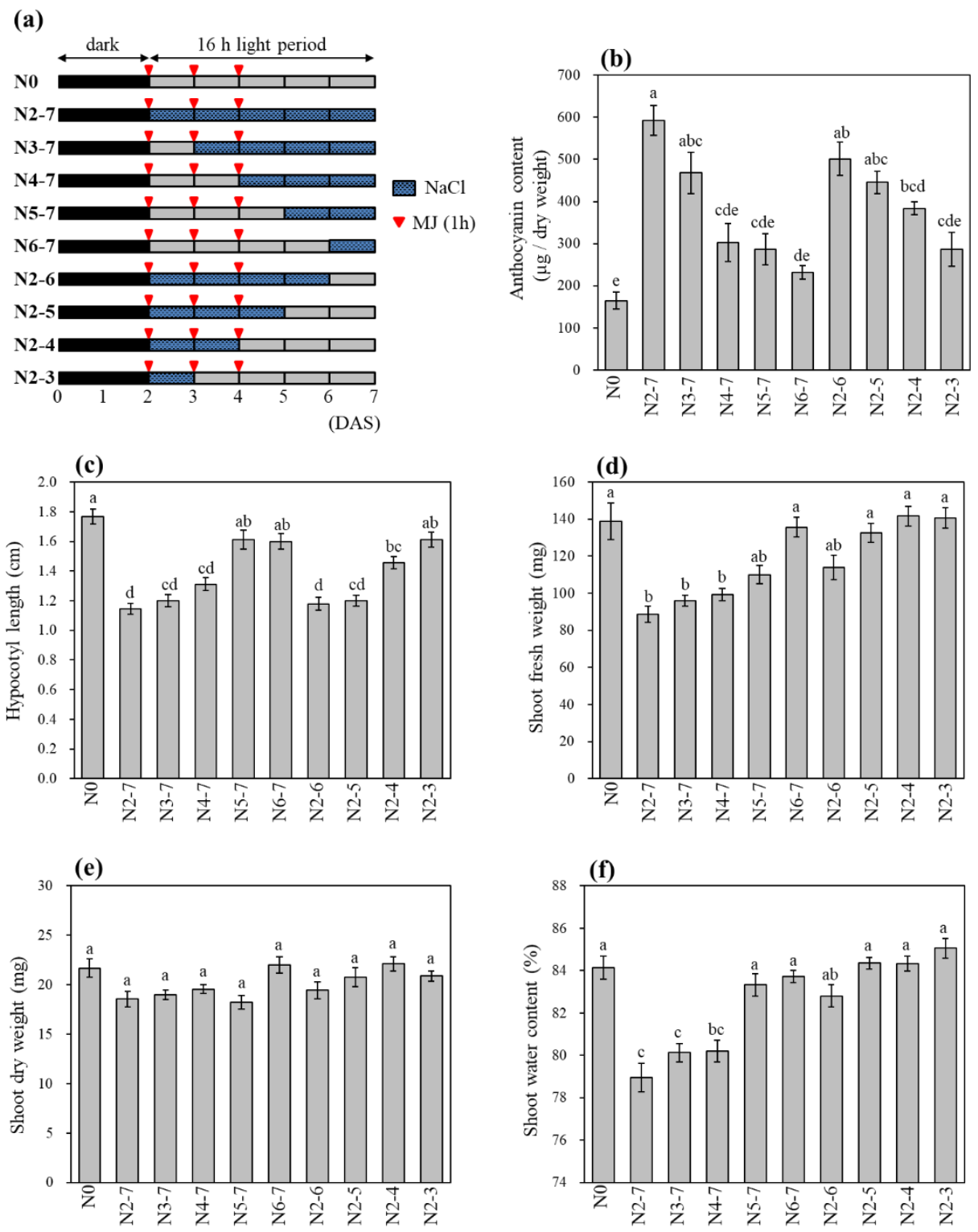

Figure 7. Effect of salinity $(200 \mathrm{mM} \mathrm{NaCl})$ treatment periods on the growth of radish sprouts co-treated with MJ (0.5 mM). (a) Schematic designs of this experiment. Anthocyanin content (b), hypocotyl length (c), shoot fresh weight (d), shoot dry weight (e), and shoot water content (f) were measured in the sprouts of each treatment at 7 DAS. Error bars represent $\pm \operatorname{SE}(n=9)$. Different letters indicate significant differences by Tukey's multiple comparison test $(P<0.05)$.

\section{Discussion}

Salinity is considered to be one of the major abiotic stresses in terms of restricting plant growth [6]. In seedlings of several species, salinity stress caused reduced germination and plant biomass [41-43]. In buckwheat sprouts, continuous salinity treatment reduced weight and increased the concentration of total phenolic compounds and DPPH radical scavenging capacity [43]. In accordance with this, we showed with radish sprouts that salinity treatment $(200 \mathrm{mM})$ alone reduced hypocotyl length and plant biomass, accompanied by the accumulation of hydrogen peroxide and increased antioxidant properties such as total phenol content and DPPH radical scavenging capacity (Figures 2 and 4). Owing to salinity-induced ROS accumulation causing oxidative damage, growth retardation, and cell death [44], salinity-induced hydrogen peroxide in the present study might also act as a detrimental factor for sprout cell growth. Combined MJ and salinity treatments resulted in greater growth inhibition as compared to growth inhibition achieved through salinity alone (Figure 2). In Arabidopsis seedlings, 
combined MJ and salinity treatment reduced root growth [45]. In contrast, exogenous MJ increased tolerance to salinity stress and ameliorated stress-induced growth inhibition by enhancing antioxidant properties in wheat seedlings [46]. Given that sustained JA signaling has been proposed to act as a deleterious factor for plant cells under salt stress conditions [47], the continuous MJ treatments from 2 to 4 DAS in the present study could persistently activate JA signaling during salinity conditions, and hence could negatively affect sprout growth.

Anthocyanins are known to be involved in several stress responses, acting as antioxidants to alleviate plant oxidative damage [11]. In salinity-tolerant transgenic tobacco plants, anthocyanin accumulation was enhanced in parallel with the greater total polyphenol content and radical scavenging capacity, as compared with wild-type plants [48]. In the present study, MJ treatment singly induced anthocyanin accumulation, with this accumulation being enhanced by co-treatment with salinity (Figure 1). These changes were associated with increased total phenol content, radical scavenging capacity, and MDA concentration (Figure 2). Therefore, the accumulation of anthocyanin in this study might be one of the antioxidant responses to cellular oxidative stress. Importantly, the production of hydrogen peroxide was hardly observed in the sprouts treated with $\mathrm{MJ}$ alone, although other antioxidant properties were upregulated (Figure 2a). Given that MJ application has been shown to induce stress tolerance by inducing increased levels of antioxidants and antioxidative enzymes [49,50], the hydrogen peroxide production in the present study by treatment with MJ from 3 to 4 DAS may be eliminated by 7 DAS by the rapid increase in antioxidant concentration and antioxidative enzyme activity. In contrast, in sprouts treated only with salinity, the production of hydrogen peroxide was increased without accumulation of anthocyanin (Figures 2 and 3). This indicates that salinity treatment might activate antioxidant responses different from those antioxidant responses induced by MJ. In Arabidopsis, the expression of the JA-responsive genes AOS, AOC, and VSP was not induced by salinity stress alone, but by co-treatment with salinity and JA [45]. Therefore, the MJ/salinity co-treatment in this study might potentiate MJ-induced JA signaling, leading to anthocyanin synthesis. Given the report that salinity alone induced JA-responsive genes in a concentration-dependent manner [51], the anthocyanin accumulation observed in the sprouts treated with high salinity alone (Figure 4) may also result from the activation of JA signaling.

Light is known to be one of the principal anthocyanin inducers in leaves and fruits $[23,25,36,52]$. In lettuce plants, MJ-induced anthocyanin accumulation in leaves was dependent on light intensity [23]. Park et al. [25] in their study reported that in MJ-treated radish sprouts, anthocyanin content did not increase under dark conditions but increased in the light, accompanied with increased expression of a group of genes involved in anthocyanin biosynthesis, such as PAL and CHI [25]. Similar to these abovementioned studies, the present study showed that anthocyanins were not induced in the dark by any of the treatments investigated (Figure 5), indicating that light is indispensable for anthocyanin accumulation in radish sprouts. Interestingly, under the conditions of high light $\left(200 \mu \mathrm{mol} \mathrm{m} \mathrm{m}^{-2} \mathrm{~s}^{-1} \mathrm{PPF}\right)$, accumulation of anthocyanins was increased in plants treated with salinity alone compared with plants treated with MJ alone (Figure 5). In Arabidopsis, the redox-sensitive process is involved in anthocyanin synthesis under high light intensity [53]. Thus, it has been suggested that salinity treatment under high light conditions may alter the cellular redox status, resulting in activation of the redox-sensitive anthocyanin production process.

The accumulation of anthocyanins was decreased when the MJ treatment period was delayed in the sprouts co-treated with MJ and salinity (Figure 6). In tomato plants, JA treatments induced defense responses against insect larvae including several defense-related oxidative enzymes activations in a plant age-dependent manner [54]. In red leaf lettuce, young leaves showed greater anthocyanin accumulation than did old leaves in response to MJ [23]. Thus, younger sprouts may be more responsive to $\mathrm{MJ}$ in increasing anthocyanin synthesis. The accumulation of anthocyanins in response to co-treatment with MJ and salinity was also suppressed by shortening the treatment period of the salinity stress (Figure 7), indicating that continuous salinity treatment is necessary to maintain the synthesis of anthocyanins. Accumulation of anthocyanin was more strongly inhibited by delaying 
the start time of the salinity treatment as compared to delaying the end time of the salinity treatment (Figure 7). Owing to the overlap between the periods of the MJ and salinity treatments being shortened by delaying the salinity treatment start time, the duration of the period of simultaneous treatment with MJ and salinity may be important for a synergistic effect with respect to anthocyanin induction. On the other hand, growth inhibition by co-treatment with $\mathrm{MJ}$ and salinity was attenuated more by bringing forward the end time of the salinity treatment than by delaying the start time of the salinity treatment (Figure 7). Considering that the susceptibility of plants to salinity is influenced by the growth stage at which the plants are exposed to the stress [55,56], older sprouts may be more sensitive than young sprouts to the growth inhibition effect of salinity.

\section{Conclusions}

To cultivate functional crops that contain high anthocyanin concentrations, it is important to determine not only the anthocyanin concentration of individual crops, but also the total amount of biomass of the crops. In the present study, we showed that MJ-induced anthocyanin accumulation was enhanced by co-treatment with salinity, accompanied by growth restriction. This growth restriction was alleviated by shortening the end time of the salinity treatment. Such complicated stress-inducing steps could be one of the strategies for reducing growth inhibition by stress response while activating signals to induce biosynthesis of antioxidants.

Author Contributions: M.S. conceptualized the study and undertook all experiential studies and the statistical analyses and draft preparation, T.S. reviewed and edited.

Funding: This research was funded by the Kindai University research grant (17-III-5).

Conflicts of Interest: The authors declare no conflict of interest.

\section{References}

1. Fankhauser, C.; Chory, J. Light control of plant development. Annu. Rev. Cell Dev. Biol. 1997, 13, 203-229. [CrossRef] [PubMed]

2. Porter, J.R.; Gawith, M. Temperatures and the growth and development of wheat: A review. Eur. J. Agron. 1997, 10, 23-36. [CrossRef]

3. Zhao, J.; Davis, L.C.; Verpoorte, R. Elicitor signal transduction leading to production of plant secondary metabolites. Biotechnol. Adv. 2005, 23, 283-333. [CrossRef] [PubMed]

4. Namdeo, A.G. Plant cell elicitation for production of secondary metabolites: A review. Pharmacogn. Rev. 2007, 1, 69-79.

5. Akula, R.; Ravishankar, G.A. Influence of abiotic stress signals on secondary metabolites in plants. Plant Signal. Behav. 2011, 6, 1720-1731. [CrossRef] [PubMed]

6. Parida, A.K.; Das, A.B. Salt tolerance and salinity effects on plants: A review. Ecotoxicol. Environ. Saf. 2005, 60, 324-349. [CrossRef] [PubMed]

7. Petridis, A.; Therios, I.; Samouris, G.; Tananaki, C. Salinity-induced changes in phenolic compounds in leaves and roots of four olive cultivars (Olea europaea L.) and their relationship to antioxidant activity. Environ. Exp. Bot. 2012, 79, 37-43. [CrossRef]

8. Wang, Y.C.; Qu, G.Z.; Li, H.Y.; Wu, Y.J.; Wang, C.; Liu, G.F.; Yang, C.P. Enhanced salt tolerance of transgenic poplar plants expressing a manganese superoxide dismutase from Tamarix androssowii. Mol. Biol. Rep. 2010, 37, 1119-1124. [CrossRef]

9. Joseph, B.; Jini, D.; Sujatha, S. Development of salt stress-tolerant plants by gene manipulation of antioxidant enzymes. Asian J. Agric. Res. 2011, 5, 17-27. [CrossRef]

10. Upadhyaya, C.P.; Venkatesh, J.; Gururani, M.A.; Asnin, L.; Sharma, K.; Ajappala, H.; Park, S.W. Transgenic potato overproducing L-ascorbic acid resisted an increase in methylglyoxal under salinity stress via maintaining higher reduced glutathione level and glyoxalase enzyme activity. Biotechnol. Lett. 2011, 33, 2297-2307. [CrossRef]

11. Chalker-Scott, L. Environmental significance of anthocyanins in plant stress responses. Photochem. Photobiol. 1999, 70, 1-9. [CrossRef] 
12. Nagata, T.; Todoriki, S.; Masumizu, T.; Suda, I.; Furuta, S.; Du, Z.; Kikuchi, S. Levels of active oxygen species are controlled by ascorbic acid and anthocyanin in Arabidopsis. J. Agric. Food Chem. 2003, 7, 2992-2999. [CrossRef] [PubMed]

13. Sakamoto, M.; Suzuki, T. Effect of root-zone temperature on growth and quality of hydroponically grown red leaf lettuce (Lactuca sativa L. cv. Red Wave). Am. J. Plant Sci. 2015, 6, 2350-2360. [CrossRef]

14. Eryılmaz, F. The relationships between salt stress and anthocyanin content in higher plants. Biotechnol. Biotechnol. Equip. 2006, 20, 47-52. [CrossRef]

15. Wahid, A.; Ghazanfar, A. Possible involvement of some secondary metabolites in salt tolerance of sugarcane. J. Plant Physiol. 2006, 163, 723-730. [CrossRef]

16. Chutipaijit, S.; Cha-um, S.; Sompornpailin, K. High contents of proline and anthocyanin increase protective response to salinity in 'Oryza sativa' L. spp. 'indica'. Aust. J. Crop Sci. 2011, 5, 1191-1198.

17. Cheong, J.J.; Do Choi, Y. Methyl jasmonate as a vital substance in plants. Trends Genet. 2003, 19, 409-413. [CrossRef]

18. Saniewski, M.; Miszczak, A.; Kawa-Miszczak, L.; Wegrzynowicz-Lesiak, E.; Miyamoto, K.; Ueda, J. Effects of methyl jasmonate on anthocyanin accumulation, ethylene production, and $\mathrm{CO}_{2}$ evolution in uncooled and cooled tulip bulbs. J. Plant Growth Reg. 1998, 17, 33-37. [CrossRef]

19. Rudell, D.R.; Mattheis, J.P.; Fan, X.; Fellman, J.K. Methyl jasmonate enhances anthocyanin accumulation and modifies production of phenolics and pigments in 'Fuji' apples. J. Am. Soc. Hortic. Sci. 2002, 127, 435-441. [CrossRef]

20. Ali, M.B.; Hahn, E.J.; Paek, K.Y. Methyl jasmonate and salicylic acid induced oxidative stress and accumulation of phenolics in Panax ginseng bioreactor root suspension cultures. Molecules 2007, 12, 607-621. [CrossRef]

21. Heredia, J.B.; Cisneros-Zevallos, L. The effects of exogenous ethylene and methyl jasmonate on the accumulation of phenolic antioxidants in selected whole and wounded fresh produce. Food Chem. 2009, 115, 1500-1508. [CrossRef]

22. Shan, X.; Zhang, Y.; Peng, W.; Wang, Z.; Xie, D. Molecular mechanism for jasmonate-induction of anthocyanin accumulation in Arabidopsis. J. Exp. Bot. 2009, 60, 3849-3860. [CrossRef] [PubMed]

23. Sakamoto, M.; Suzuki, T. Effects of plant defense elicitors on anthocyanin accumulation in red baby leaf lettuce. Mem. Fac. Biol.-Oriented Sci. Technol. Kinki Univ. 2015, 35, 1-6.

24. Sakamoto, M.; Suzuki, T. Synergistic effects of a night temperature shift and methyl jasmonate on the production of anthocyanin in red leaf lettuce. Am. J. Plant Sci. 2017, 8, 1534-1549. [CrossRef]

25. Park, W.T.; Kim, Y.B.; Seo, J.M.; Kim, S.J.; Chung, E.; Lee, J.H.; Park, S.U. Accumulation of anthocyanin and associated gene expression in radish sprouts exposed to light and methyl jasmonate. J. Agric. Food Chem. 2013, 61, 4127-4132. [CrossRef] [PubMed]

26. Qi, T.; Song, S.; Ren, Q.; Wu, D.; Huang, H.; Chen, Y.; Fan, M.; Peng, W.; Ren, C.; Xie, D. The Jasmonate-ZIM-domain proteins interact with the WD-Repeat/bHLH/MYB complexes to regulate Jasmonate-mediated anthocyanin accumulation and trichome initiation in Arabidopsis thaliana. Plant Cell 2011, 23, 1795-1814. [CrossRef] [PubMed]

27. Ross, J.A.; Kasum, C.M. Dietary flavonoids: Bioavailability, metabolic effects, and safety. Annu. Rev. Nutr. 2002, 22, 19-34. [CrossRef] [PubMed]

28. Stintzing, F.C.; Carle, R. Functional properties of anthocyanins and betalains in plants, food, and in human nutrition. Trends Food Sci. Technol. 2004, 15, 19-38. [CrossRef]

29. Sayyari, M.; Babalar, M.; Kalantari, S.; Martínez-Romero, D.; Guillén, F.; Serrano, M.; Valero, D. Vapour treatments with methyl salicylate or methyl jasmonate alleviated chilling injury and enhanced antioxidant potential during postharvest storage of pomegranates. Food Chem. 2011, 124, 964-970. [CrossRef]

30. Shafiq, M.; Singh, Z.; Ahmad, S.K. Pre-harvest spray application of methyl jasmonate improves red blush and flavonoid content in 'Cripps Pink' apple. J. Hort. Sci. Biotechnol. 2011, 86, 422-430. [CrossRef]

31. Huang, X.; Li, J.; Shang, H.; Meng, X. Effect of methyl jasmonate on the anthocyanin content and antioxidant activity of blueberries during cold storage. J. Sci. Food Agric. 2015, 95, 337-343. [CrossRef] [PubMed]

32. Gazula, A.; Kleinhenz, M.D.; Streeter, J.G.; Miller, A.R. Temperature and cultivar effects on anthocyanin and chlorophyll b concentrations in three related Lollo Rosso lettuce cultivars. HortScience 2005, 40, 1731-1733. [CrossRef] 
33. Li, Q.; Kubota, C. Effects of supplemental light quality on growth and phytochemicals of baby leaf lettuce. Environ. Exp. Bot. 2009, 67, 59-64. [CrossRef]

34. Biesiada, A.; Tomczak, A. Biotic and abiotic factors affecting the content of the chosen antioxidant compounds in vegetables. Veg. Crops Res. Bull. 2012, 76, 55-78. [CrossRef]

35. Do, C.B.; Cormier, F. Accumulation of peonidin 3-glucoside enhanced by osmotic stress in grape (Vitis vinifera L.) cell suspension. Plant Cell Tissue Organ Cult. 1991, 24, 49-54. [CrossRef]

36. Giraud, E.; Ho, L.H.; Clifton, R.; Carroll, A.; Estavillo, G.; Tan, Y.F.; Howell, K.A.; Ivanova, A.; Pogson, B.J.; Millar, A.H.; et al. The absence of ALTERNATIVE OXIDASE1a in Arabidopsis results in acute sensitivity to combined light and drought stress. Plant Physiol. 2008, 147, 595-610. [CrossRef] [PubMed]

37. Tassoni, A.; Durante, L.; Ferri, M. Combined elicitation of methyl-jasmonate and red light on stilbene and anthocyanin biosynthesis. J. Plant Physiol. 2012, 169, 775-781. [CrossRef] [PubMed]

38. Leja, M.; Kamińska, I.; Kramer, M.; Maksylewicz-Kaul, A.; Kammerer, D.; Carle, R.; Baranski, R. The content of phenolic compounds and radical scavenging activity varies with carrot origin and root color. Plant Foods Hum. Nutr. 2013, 68, 163-170. [CrossRef] [PubMed]

39. Li, S.J.; Bai, Y.C.; Li, C.L.; Yao, H.P.; Chen, H.; Zhao, H.X.; Wu, Q. Anthocyanins accumulate in tartary buckwheat (Fagopyrum tataricum) sprout in response to cold stress. Acta Physiol. Plant. 2015, 37, 159. [CrossRef]

40. Steyn, W.J.; Wand, S.J.E.; Holcroft, D.M.; Jacobs, G. Anthocyanins in vegetative tissues: A proposed unified function in photoprotection. New Phytol. 2002, 155, 349-361. [CrossRef]

41. Akhtar, S.; Wahid, A.; Rasul, E. Emergence, growth and nutrient composition of sugarcane sprouts under $\mathrm{NaCl}$ salinity. Biol. Plant. 2003, 46, 113-116. [CrossRef]

42. Lim, J.H.; Park, K.J.; Kim, B.K.; Jeong, J.W.; Kim, H.J. Effect of salinity stress on phenolic compounds and carotenoids in buckwheat (Fagopyrum esculentum M.) sprout. Food Chem. 2012, 135, 1065-1070. [CrossRef] [PubMed]

43. Moghbeli, E.; Fathollahi, S.; Salari, H.; Ahmadi, G.; Saliqehdar, F.; Safari, A.; Grouh, M.S.H. Effects of salinity stress on growth and yield of Aloe vera L. J. Med. Plants Res. 2012, 6, 3272-3277.

44. Quan, L.J.; Zhang, B.; Shi, W.W.; Li, H.Y. Hydrogen peroxide in plants: A versatile molecule of the reactive oxygen species network. J. Integr. Plant Biol. 2008, 50, 2-18. [CrossRef] [PubMed]

45. Chen, Y.; Wang, Y.; Huang, J.; Zheng, C.; Cai, C.; Wang, Q.; Wu, C.A. Salt and methyl jasmonate aggravate growth inhibition and senescence in Arabidopsis seedlings via the JA signaling pathway. Plant Sci. 2017, 261, 1-9. [CrossRef]

46. Qiu, Z.; Guo, J.; Zhu, A.; Zhang, L.; Zhang, M. Exogenous jasmonic acid can enhance tolerance of wheat seedlings to salt stress. Ecotoxicol. Environ. Saf. 2014, 104, 202-208. [CrossRef] [PubMed]

47. Ismail, A.; Takeda, S.; Nick, P. Life and death under salt stress: Same players, different timing? J. Exp. Bot. 2014, 65, 2963-2979. [CrossRef]

48. Naing, A.H.; Park, K.I.; Ai, T.N.; Chung, M.Y.; Han, J.S.; Kang, Y.W.; Lim, K.B.; Kim, C.K. Overexpression of snapdragon Delila (Del) gene in tobacco enhances anthocyanin accumulation and abiotic stress tolerance. BMC Plant Biol. 2017, 17, 65. [CrossRef]

49. Cao, S.; Zheng, Y.; Wang, K.; Jin, P.; Rui, H. Methyl jasmonate reduces chilling injury and enhances antioxidant enzyme activity in postharvest loquat fruit. Food Chem. 2009, 115, 1458-1463. [CrossRef]

50. Anjum, S.A.; Wang, L.; Farooq, M.; Khan, I.; Xue, L. Methyl jasmonate-induced alteration in lipid peroxidation, antioxidative defence system and yield in soybean under drought. J. Agron. Crop Sci. 2011, 197, 296-301. [CrossRef]

51. Ismail, A.; Riemann, M.; Nick, P. The jasmonate pathway mediates salt tolerance in grapevines. J. Exp. Bot. 2012, 63, 2127-2139. [CrossRef] [PubMed]

52. Takos, A.M.; Jaffé, F.W.; Jacob, S.R.; Bogs, J.; Robinson, S.P.; Walker, A.R. Light-induced expression of a MYB gene regulates anthocyanin biosynthesis in red apples. Plant Physiol. 2006, 142, 1216-1232. [CrossRef] [PubMed]

53. Page, M.; Sultana, N.; Paszkiewicz, K.; Florance, H.; Smirnoff, N. The influence of ascorbate on anthocyanin accumulation during high light acclimation in Arabidopsis thaliana: Further evidence for redox control of anthocyanin synthesis. Plant Cell Environ. 2012, 35, 388-404. [CrossRef] [PubMed]

54. Cipollini, D.F.; Redman, A.M. Age-dependent effects of jasmonic acid treatment and wind exposure on foliar oxidase activity and insect resistance in tomato. J. Chem. Ecol. 1999, 25, 271-281. [CrossRef] 
55. Steppuhn, H.; Wall, K.G. Grain yields from spring-sown Canadian wheats grown in saline rooting media. Can. J. Plant Sci. 1997, 77, 63-68. [CrossRef]

56. Carvajal, M.; del Amor, F.M.; Fernandez-Ballester, G.; Martinez, V.; Cerdá, A. Time course of solute accumulation and water relations in muskmelon plants exposed to salt during different growth stages. Plant Sci. 1998, 138, 103-112. [CrossRef] 